\title{
Pharmacopsychology as a Basic and Applied Science: Announcement of Review Papers on Basic Topics
}

Pharmacopsychology as the science which investigates the effects of chemical agents on the behavior of normal human and animal subjects has become a discipline which involves various subdisci-plines each having its own research purposes and methodology. At the present time it seems that three areas have been developed as the most influential ones:

First, pharmacopsychology as a field which uses drugs as research tools for elucidating behavioral processes, e.g. personality, development, learning, emotion and motivation, performance and action. The use of drugs as research tools in psychology has been introduced and discussed more than 20 years ago [Eysenck, 1961; Kornetsky, 1961; Russell, 1961, 1964; Janke, 1962]. Since then the usefulness of this strategy has increased by the development of drugs which have relatively specific actions and action mechanisms.

The second area which is usually regarded as the most important one refers to the prediction of clinical effectiveness of drugs by means of normal human or animal subjects. Gradually it has become clear that it is possible to make rather good predictions if we use adequate prediction models.

A third field of pharmacopsychology which has been relatively neglected in research may be called applied pharmacopsychology. This area refers to the application of behavioral drug studies in various fields of applied psychology. Examples may be traffic psychology, industrial psychology or abnormal psychology.

In the text issues of the section 'Biological Psychology/Pharma-copsychology' the three areas of pharmacopsychology will be re-

viewed and discussed by prominent authors. It is expected that these review papers will not only demonstrate to what extent hopes arising about 25 years ago have been fulfilled or failed, but will stimulate further research and abolish some misunderstandings which are often found in other fields of psychopharmacology.

In this issue Prof. H.I. Eysenck will open the review series on 'Drugs as Research Tools in Psychology'. Prof. Eysenck is one of the pioneers in this field. In one of the next issues the review series 'Prediction of Clinical Effectiveness of Drugs by Preclinical Data' will start.

References Eysenck, H.J.: Drugs and the validation of typological hypotheses.

Acta psychol. 19: 761-789 (1961). Janke, W.: Über die Bedeutung pharmakopsychologischer Untersu-

chungen für die psychologische Grundlagenforschung. Sber. Ges.

Befórd. ges. Naturw. Marburg 84: 277-296 (1962). Kornetsky, C: Individual differences in response to drugs. Acta psychol. 79:765-771 (1961). Russell, R.W.: Hypotheses testable experimentally by the use of drugs as research tools. Acta psychol. 19: 77'5-777 (1961). Russell, R.W.: Drugs as tools in behavioral research; in Uhr, Miller,

Drugs and behavior, pp. $19^{\wedge} 10$ (Wiley, New York 1964).

Wilhelm Janke, Würzburg 